\title{
Commentary: Gray Matter Structural Alterations in Social Anxiety Disorder: A Voxel-Based Meta-Analysis
}

\author{
Janna Marie Bas-Hoogendam ${ }^{1,2,3 *}$ \\ ${ }^{1}$ Institute of Psychology, Leiden University, Leiden, Netherlands, ${ }^{2}$ Department of Psychiatry, Leiden University Medical \\ Center, Leiden, Netherlands, ${ }^{3}$ Leiden Institute for Brain and Cognition, Leiden, Netherlands
}

Keywords: social anxiety disorder, structural magnetic resonance imaging, gray matter volume, meta-analysis, voxel-based morphometry

\section{A Commentary on}

Gray Matter Structural Alterations in Social Anxiety Disorder: A Voxel-Based Meta-Analysis by Wang, X., Cheng, B., Luo, Q., Qiu, L., and Wang, S. (2018). Front. Psychiatry 9:449. doi: $10.3389 /$ fpsyt.2018.00449

\section{OPEN ACCESS}

Edited by:

Cynthia H. Y. Fu,

University of East London,

United Kingdom

Reviewed by:

Song Wang,

Sichuan University, China

*Correspondence:

Janna Marie Bas-Hoogendam j.m.hoogendam@fsw.leidenuniv.nl orcid.org/0000-0001-8982-1670

Specialty section:

This article was submitted to

Mood and Anxiety Disorders,

a section of the journal

Frontiers in Psychiatry

Received: 12 November 2018 Accepted: 02 January 2019

Published: 22 January 2019

Citation:

Bas-Hoogendam JM (2019) Commentary: Gray Matter Structural Alterations in Social Anxiety Disorder:

A Voxel-Based Meta-Analysis.

Front. Psychiatry 10:1.

doi: 10.3389/fpsyt.2019.00001

\section{INTRODUCTION}

Social anxiety disorder (SAD), an impairing and often chronic psychiatric disorder (1), has a lifetime prevalence between 6 and 13\% (2-5) and is prevailing worldwide (6). At present, treatment for SAD is often suboptimal (7-10). Insight in the neurobiological changes underlying the socially-anxious brain is of utmost importance to improve preventive and therapeutic interventions.

Until now, several studies have examined alterations in brain structure associated with SAD, by using magnetic resonance imaging (MRI). This method enables investigating changes in gray matter (GM) (11). Results of MRI studies on GM characteristics related to SAD show, however, little consistency and have small effect sizes (12-14).

Recently, Wang et al. (15) described a voxel-based meta-analysis on GM volume (GMV) differences between SAD-patients and healthy participants. Such a meta-analytic review is very welcome in order to quantitatively summarize the results of previously published studies and to further increase our understanding of SAD-related GMV alterations. Unfortunately, the paper did not live up to its promise. Wang et al. state that SAD is associated with increased cortical and decreased subcortical GMVs, but these conclusions cannot be deduced from their data. Here, we want to point out several shortcomings that seriously affect this work.

\section{METHODOLOGICAL ISSUES}

To start, several methodological details limit the authors' conclusions. First, the description of the analytical approach lacks clarity. According to the methods, "peak coordinates data of GMV differences found significant at the whole-brain level" were used to create maps of the effect size of GMV differences for each study, but three studies included in the meta-analysis did not report significant group differences at the whole-brain level (16-18) and two reported effects at an uncorrected significance level only $(19,20)$. Furthermore, the authors did not explain how the sensitivity analysis, discarding one study at a time, handles studies reporting null-effects. 
Another methodological issue concerns the subgroup analysis on adult SAD-patients. This analysis includes 384 patients (all $>18$ years according to the methods, or $\geq 18$ years according to the abstract), while the main analysis contained 480 patients. As the authors do not provide an overview of the samples which were excluded, we examined the study characteristics [Table 1 of the original article by Wang et al. (15)] and compared the number of participants. We assume that studies for which data on the agerange were, according to the authors, not available, were excluded $(18,21,22)$. However, when reading the original papers, it seems very likely that these excluded studies also concern adult SADpatients. This means that the different results of the subgroup analysis, compared to the main analysis, are most likely caused by changes in statistical power and cannot be attributed to ageeffects. Future studies are needed to investigate the effect of age on SAD-related GMV alterations.

\section{DISCUSSION OF RESULTS}

Next, we feel the findings deserve more nuanced attention than the authors currently provide in the Discussion. In addition, findings of previous studies are not reflected accurately. We highlight two examples.

The first concerns the discussion of the precuneus results. The authors link their results of increased GMV in the left precuneus to the findings of "increased cortical thickness of the precuneus" by Brühl et al. (23) and Syal et al. (24). However, Syal and colleagues actually reported a thinning of the left precuneus related to SAD, implying decreased GMV.

Another example involves the authors' argumentation with respect to the GMV reduction in the left putamen. The authors argue that the age-related reduction in putamen volume in SADpatients, reported by Potts et al. (25), is in line with their finding. We don't agree with this statement: Potts and colleagues indicate that there is "no statistically significant difference between social phobia patients and normal control subjects"; the "age-related reduction in putamen volumes in patients with social phobia that was greater than that seen in controls" (25) cannot be equated with the group difference reported in the present metaanalysis. Furthermore, it should be noted that recent work on putamen volume in $\mathrm{SAD}$, which was probably not yet available at the time the meta-analysis was performed, implies changes in the opposite direction, namely increased GMV in the dorsal striatum in $\operatorname{SAD}(14,16)$; these findings are supported by a positive relationship between social anxiety and GMV in the putamen in healthy women (26) and a positive correlation between the concept "intolerance of uncertainty" and putamen volume (27).

\section{MISREPRESENTATION OF PREVIOUS STUDIES}

The authors repeatedly miss the chance to summarize the details of the studies included in the meta-analysis in an insightful and correct way. For example, Table 1 (15) indicates that the paper describing a mega-analysis on the largest database of SAD structural MRI scans to date (16) and the paper by Irle et al. (19) do not provide scores on the Liebowitz Social Anxiety Scale (LSAS); these scores are, however, available for the majority of the SAD-patients (148/174) included in the mega-analysis (16), while the paper by Irle et al. reported scores on the two dimension scales of the LSAS (19). Furthermore, the authors inaccurately indicate that the paper by Meng et al. (28) does not provide the age of onset of SAD, while the number of SAD-patients taking medication in the study by Månsson et al. (20) is incorrectly reproduced.

Next, the main text of the paper does not always provide a comprehensive overview of ongoing research in SAD. For example, the authors describe that "only a few studies of SAD have explicitly controlled for depression comorbidity," referring to three papers which are not part of the present meta-analysis $(23,24,29)$. This is a valid point. However, the authors fail to mention that, given the high comorbidity rate between depression and SAD (30), completely excluding SADpatients with comorbid depression could lead to biased results, as this could implicate that severe SAD-cases are excluded. In order to account for this comorbidity, sensitivity analyses, such as described by Bas-Hoogendam et al. (16) and Irle et al. (19), provide valuable information and deserve to be mentioned.

\section{CONCLUSION AND RECOMMENDATIONS}

To conclude, the results presented by Wang et al. need to be interpreted with caution. On the basis of the present meta-analysis, it is premature to conclude that SAD is associated with increased cortical and decreased subcortical GMVs. Meta-analyses on larger samples (31-33) are needed to improve our understanding of the SAD-related structural brain alterations.

\section{AUTHOR CONTRIBUTIONS}

The author confirms being the sole contributor of this work and has approved it for publication.

\section{FUNDING}

JMB-H is funded by Leiden University Research Profile Health, Prevention, and the Human Life Cycle and the Institute of Psychology of Leiden University.

\section{ACKNOWLEDGMENTS}

We thank Dr. Henk van Steenbergen, Prof. Dr. Nic J. A. van der Wee, and Prof. Dr. P. Michiel Westenberg for their feedback on a previous version of this commentary. 


\section{REFERENCES}

1. Stein MB, Stein DJ. Social anxiety disorder. Lancet (2008) 371:1115-25. doi: 10.1016/S0140-6736(08)60488-2

2. Stein DJ, Ruscio AM, Lee S, Petukhova M, Alonso J, Andrade LHSG, et al. Subtyping social anxiety disorder in developed and developing countries. Depress Anxiety (2010) 27:390-403. doi: 10.1002/da.20639

3. Kessler RC, Petukhova M, Sampson NA, Zaslavsky AM, Wittchen H-U. Twelve-month and lifetime prevalence and lifetime morbid risk of anxiety and mood disorders in the United States. Int J Methods Psychiatr Res. (2012) 21:169-84. doi: 10.1002/mpr.1359

4. Bandelow B, Michaelis S. Epidemiology of anxiety disorders in the 21st century. Dialogues Clin Neurosci. (2015) 17:327-35.

5. Ruscio AM, Brown TA, Chiu WT, Sareen J, Stein MB, Kessler RC. Social fears and social phobia in the USA: results from the National Comorbidity Survey Replication. Psychol Med. (2008) 38:15-28. doi: 10.1017/S0033291707 001699

6. Stein DJ, Lim CCW, Roest AM, de Jonge P, Aguilar-Gaxiola S, Al-Hamzawi A, et al. The cross-national epidemiology of social anxiety disorder: data from the World Mental Health Survey Initiative. BMC Med. (2017) 15:143. doi: 10.1186/s12916-017-0889-2

7. Carpenter JK, Andrews LA, Witcraft SM, Powers MB, Smits JAJ, Hofmann SG. Cognitive behavioral therapy for anxiety and related disorders: a meta-analysis of randomized placebo-controlled trials. Depress Anxiety (2018) 35:502-14. doi: $10.1002 /$ da. 22728

8. Weisberg RB, Beard C, Moitra E, Dyck I, Keller MB. Adequacy of treatment received by primary care patients with anxiety disorders. Depress Anxiety (2014) 31:443-50. doi: 10.1002/da.22209

9. Alonso J, Liu Z, Evans-Lacko S, Sadikova E, Sampson N, Chatterji S, et al. Treatment gap for anxiety disorders is global: results of the World Mental Health Surveys in 21 countries. Depress Anxiety (2018) 35:195-208. doi: $10.1002 /$ da. 22711

10. Canton J, Scott KM, Glue P. Optimal treatment of social phobia: systematic review and meta-analysis. Neuropsychiatr Dis Treat. (2012) 8:203-15. doi: $10.2147 /$ NDT.S23317

11. Lerch JP, van der Kouwe AJW, Raznahan A, Paus T, Johansen-Berg H, Miller KL, et al. Studying neuroanatomy using MRI. Nat Neurosci. (2017) 20:314-26. doi: 10.1038/nn.4501

12. Brühl AB, Delsignore A, Komossa K, Weidt S. Neuroimaging in Social Anxiety Disorder-a meta-analytic review resulting in a new neurofunctional model. Neurosci Biobehav Rev. (2014) 47:260-80. doi: 10.1016/j.neubiorev.2014.08.003

13. Bas-Hoogendam JM, Blackford JU, Brühl AB, Blair KS, van der Wee NJA, Westenberg PM. Neurobiological candidate endophenotypes of social anxiety disorder. Neurosci Biobehav Rev. (2016) 71:362-78. doi: 10.1016/j.neubiorev.2016.08.040

14. Bas-Hoogendam JM, van Steenbergen H, Tissier RLM, Houwing-Duistermaat JJ, Westenberg PM, van der Wee NJA. Subcortical brain volumes, cortical thickness and cortical surface area in families genetically enriched for social anxiety disorder - A multiplex multigenerational neuroimaging study. EBioMedicine (2018) 36:410-28. doi: 10.1016/j.ebiom.2018.08.048

15. Wang X, Cheng B, Luo Q, Qiu L, Wang S. Gray matter structural alterations in social anxiety disorder: a voxel-based meta-analysis. Front Psychiatry (2018) 9:449. doi: 10.3389/fpsyt.2018.00449

16. Bas-Hoogendam JM, van Steenbergen H, Pannekoek JN, Fouche J-P, Lochner C, Hattingh CJ, et al. Voxel-based morphometry multi-center mega-analysis of brain structure in social anxiety disorder. Neuroimage Clin. (2017) 16:67888. doi: 10.1016/j.nicl.2017.08.001

17. Kawaguchi A, Nemoto K, Nakaaki S, Kawaguchi T, Kan H, Arai N, et al. Insular volume reduction in patients with social anxiety disorder. Front Psychiatry (2016) 7:3. doi: 10.3389/fpsyt.2016.00003

18. Cheng B, Huang X, Li S, Hu X, Luo Y, Wang X, et al. Gray matter alterations in post-traumatic stress disorder, obsessive-compulsive disorder, and social anxiety disorder. Front Behav Neurosci. (2015) 9:219. doi: 10.3389/fnbeh.2015.00219
19. Irle E, Barke A, Lange C, Ruhleder M. Parietal abnormalities are related to avoidance in social anxiety disorder: a study using voxel-based morphometry and manual volumetry. Psychiatry Res. (2014) 224:175-83. doi: 10.1016/j.pscychresns.2014.08.013

20. Månsson KNT, Salami A, Frick A, Carlbring P, Andersson G, Furmark T, et al. Neuroplasticity in response to cognitive behavior therapy for social anxiety disorder. Transl Psychiatry (2016) 6:e727. doi: 10.1038/tp.2015.218

21. Frick A, Engman J, Alaie I, Björkstrand J, Faria V, Gingnell M, et al. Enlargement of visual processing regions in social anxiety disorder is related to symptom severity. Neurosci Lett. (2014) 583:114-9. doi: 10.1016/j.neulet.2014.09.033

22. Liao W, Xu Q, Mantini D, Ding J, Machado-de-Sousa JP, Hallak JEC, et al. Altered gray matter morphometry and resting-state functional and structural connectivity in social anxiety disorder. Brain Res. (2011) 1388:16777. doi: 10.1016/j.brainres.2011.03.018

23. Brühl AB, Hänggi J, Baur V, Rufer M, Delsignore A, Weidt S, et al. Increased cortical thickness in a frontoparietal network in social anxiety disorder. Hum Brain Mapp. (2014) 35:2966-77. doi: 10.1002/hbm.22378

24. Syal S, Hattingh CJ, Fouché J-P, Spottiswoode B, Carey PD, Lochner C, et al. Grey matter abnormalities in social anxiety disorder: a pilot study. Metab Brain Dis. (2012) 27:299-309. doi: 10.1007/s11011-012-9299-5

25. Potts NL, Davidson JR, Krishnan KR, Doraiswamy PM. Magnetic resonance imaging in social phobia. Psychiatry Res. (1994) 52:35-42. doi: 10.1016/0165-1781(94)90118-X

26. Günther V, Ihme K, Kersting A, Hoffmann K-T, Lobsien D, Suslow T. Volumetric associations between amygdala, nucleus accumbens, and socially anxious tendencies in healthy women. Neuroscience (2018) 374:25-32. doi: 10.1016/j.neuroscience.2018.01.034

27. Kim MJ, Shin J, Taylor JM, Mattek AM, Chavez SJ, Whalen PJ. Intolerance of uncertainty predicts increased striatal volume. Emotion (2017) 17:895-99. doi: 10.1037/emo0000331

28. Meng Y, Lui S, Qiu C, Qiu L, Lama S, Huang X, et al. Neuroanatomical deficits in drug-naïve adult patients with generalized social anxiety disorder: a voxel-based morphometry study. Psychiatry Res. (2013) 214:9-15. doi: 10.1016/j.pscychresns.2013.06.002

29. van Tol M-J, van der Wee NJA, van den Heuvel OA, Nielen MMA, Demenescu LR, Aleman A, et al. Regional brain volume in depression and anxiety disorders. Arch Gen Psychiatry (2010) 67:1002-11. doi: 10.1001/archgenpsychiatry.2010.121

30. Beesdo K, Bittner A, Pine DS, Stein MB, Höfler M, Lieb R, et al. Incidence of social anxiety disorder and the consistent risk for secondary depression in the first three decades of life. Arch Gen Psychiatry (2007) 64:903-12. doi: 10.1001/archpsyc.64.8.903

31. Groenewold N, Bas-Hoogendam JM, Amod AR, van Velzen L, Aghajani M, Filippi C, et al. F27. Subcortical volumes in social anxiety disorder: preliminary results from enigma-anxiety. Biol Psychiatry (2018) 83:S247-8. doi: 10.1016/j.biopsych.2018.02.640

32. Bearden CE, Thompson PM. Emerging global initiatives in neurogenetics: the Enhancing Neuroimaging Genetics through Meta-analysis (ENIGMA) Consortium. Neuron (2017) 94:232-6. doi: 10.1016/j.neuron.2017.03.033

33. Thompson PM, Stein JL, Medland SE, Hibar DP, Vasquez AA, Renteria $\mathrm{ME}$, et al. The ENIGMA Consortium: large-scale collaborative analyses of neuroimaging and genetic data. Brain Imaging Behav. (2014) 8:153-82. doi: $10.1007 /$ s11682-013-9269-5

Conflict of Interest Statement: The author declares that the research was conducted in the absence of any commercial or financial relationships that could be construed as a potential conflict of interest.

Copyright (c) 2019 Bas-Hoogendam. This is an open-access article distributed under the terms of the Creative Commons Attribution License (CC BY). The use, distribution or reproduction in other forums is permitted, provided the original author(s) and the copyright owner(s) are credited and that the original publication in this journal is cited, in accordance with accepted academic practice. No use, distribution or reproduction is permitted which does not comply with these terms. 